\title{
A test of the complementary gene model for the control of biparental plastid inheritance in zonal pelargoniums
}

\author{
H. M. AMOATEY \& R. A. E. TILNEY-BASSETT†* \\ Biology Department, Ghana Atomic Energy Commission, PO Box 80, Legon, Ghana and tSchool of Biological Sciences, \\ University College of Swansea, Singleton Park, Swansea SA2 8PP, U.K.
}

\begin{abstract}
Zonal pelargoniums have a mixed plastid inheritance. After $\mathrm{G} \times \mathrm{W}$ plastid crosses, the progeny are a mixture of green, variegated and white embryos corresponding to a maternal, biparental or paternal plastid inheritance. There are two patterns of segregation: type I females produce families with a majority of green embryos, variegated intermediate and white least frequent. Type II females give rise to families in which green and white embryos are of about the same frequency and variegated the least common. The complementary gene model proposes that the alternative patterns are determined by two genes called Prl/prl and Pr2/pr2. Plants giving rise to the type II pattern contain one or two copies of the dominant alleles of both genes whereas in the absence of either one or both dominant alleles the plants are type I. The model was tested and confirmed in the classical Mendelian manner in which a single cross between two different true-breeding type I plants was followed by scoring the parents, the $F_{1}$ hybrid progeny and the $F_{2}$ and backcross generations. The results supported the interpretation that one type I parent had the genotype $\operatorname{PrlPrl}, p r 2 p r 2$ and the other type I parent had the genotype prlprl, Pr2pr2. The range, variance and confidence limits are given for the estimates of percentage maternal plastid transmission within groups of type I and type Il plants in 18 segregating families.
\end{abstract}

Keywords: biparental plastid inheritance, complementary genes, Mendelian inheritance, Pelargonium.

\section{Introduction}

There is an increasing amount of evidence to support the hypothesis that biparental plastid inheritance in higher plants is under genetic control. A regular transmission of about 2 per cent of plastids from the male parent occurs in the inbred line Tb1-3 of Petunia hybrida (Cornu \& Dulieu, 1988). Analysis of one backcross generation supported the hypothesis that two major loci $T p 1$ and $T p 2$ determined the difference between $\mathrm{Tb} 1-3$ and a non-transmitter line Skr4 (Dulieu et al., 1990). Moreover, testing chimeral individuals as male parents suggested that genes favouring paternal transfer acted at the male gametophytic level (Derepas, 1991; Derepas \& Dulieu, 1992). Within Medicago sativa three genotypes have been recognized, one that is a strong transmitter of male plastids (301), one a weaker transmitter ( $7 \mathrm{~W}$ ) and

\footnotetext{
${ }^{*}$ Correspondence.
}

one even weaker (MS-5) (Zhu et al., 1990). The genetic basis of these differences is not yet clear but there are significant differences in the frequency of plastid nucleoids per generative cell (Shi et al., 1991), although this variation, as well as that concerning plastid number, appears to be insufficient to explain the differences in male plastid transmission (Zhu et al., 1991). Within Oenothera, in which many species have been crossed, differences between the plastids themselves appeared to be a more important modifier of biparental inheritance than differences in the nuclear genotype (Chiu et al., 1988); nevertheless, nuclear gene effects do exist.

Among cultivars of zonal pelargoniums there is good evidence for the existence of maternal nuclear genes controlling the pattern of plastid inheritance whereas paternal effects, being less obvious (TilneyBassett, 1976), have attracted less attention. Crosses between cultivars in which the plastids carry either the normal wild-type allele, green phenotype $(G)$, or a 
mutant allele, white phenotype (W), in their germ cells, produce progeny with a mixture of maternal zygotes (MZ), biparental zygotes (BPZ) and paternal zygotes $(\mathrm{PZ})$ as defined by the presence or absence of green or white plastids in the young embryos into which zygotes develop. The segregation of this mixture is scored after $\mathrm{G} \times \mathrm{W}$ crosses in which the maternal zygotes are green and the paternal zygotes white or vice versa after $\mathrm{W} \times \mathrm{G}$ crosses and the biparental zygotes variegated. After $\mathrm{G} \times \mathrm{W}$ crosses there are two distinctive segregation patterns depending on the genotype of the female parent: the type I female confers a segregation pattern among the progeny in which the maternal zygotes are frequent, biparental intermediate and paternal zygotes rare $(\mathrm{MZ}>\mathrm{BPZ}>\mathrm{PZ})$. This contrasts strongly with the type II female which confers the segregation pattern of frequent maternal and paternal zygotes with biparental zygotes the least frequent class $(\mathrm{MZ}>\mathrm{BPZ}<\mathrm{PZ})$. The type I pattern was first recognized in the progeny of $\mathrm{cv}$. 'Dolly Varden', which bred true and was therefore assumed to be homozygous, and the type II pattern was found in the progeny of cv. 'Flower of Spring', which did not breed true and was therefore assumed to be heterozygous. The two patterns were considered to be under the control of a major nuclear gene, which was symbolized as $\operatorname{Pr}$, with alternative alleles $\operatorname{Pr} I$ and $P r 2$, on the assumption that the gene controlled plastid segregation through an effect, direct or indirect, on plastid replication (Tilney-Bassett, 1973). Attempts to understand some of the segregation ratios following crosses (Kirk \& Tilney-Bassett, 1978; Tilney-Bassett, $1974,1975)$ led to the simple but not wholly satisfactory explanation (Tilney-Bassett \& Abdel-Wahab, 1982) that the $\operatorname{Pr} 2$ allele was a gametophytic lethal on the female side. Alternatively, or additionally, it was suggested that an incompatibility mechanism was involved. Since that time, new and additional crosses have led to the proposal of a complementary gene model for biparental plastid inheritance (TilneyBassett et al., 1989).

We proposed in this new model that there are two independently assorting nuclear genes, each with a pair of alternative alleles, PrI/prI and Pr2/pr2. We proposed further that the genes interact in a complementary manner; in other words the two recessives behave as isoepistatic and are epistatic to the dominant genes: $(p r I=p r 2)>\operatorname{Pr} 2, \operatorname{Pr} 1$. Hence, a green maternal parent, containing one or two copies of both dominant alleles, produces the type II plastid segregation pattern after being pollinated by a variegated male carrying a mutant white plastid in its germ line whereas a maternal parent, lacking the two dominant alleles of one or other or both genes, produces the type I plastid segregation pattern. Hence, among type II plants we expect four genotypes: PrlPr1,Pr2Pr2; PrIpr1,Pr2Pr2; PrIPr1,Pr2pr2; PrIpr1,Pr2pr2 and among type I plants we expect five genotypes: prlpr1,Pr2Pr2; Pr1Pr1,pr2pr2; prIprI,Pr2pr2; PrIpr1,pr2pr2; prlpr1,pr2pr2. After a $9 \times 9$ matrix of crosses of type II and type I genotypes, there are 81 combinations: nine of these are selfs and 72 are crosses but if we combine reciprocals this reduces to 36 crosses. Depending upon the precise parental genotypes, there are 10 selfs or crosses within type IIs, 15 within type Is and 20 between type IIs and type Is. By referring to Table 1, we can see the expected progenies after any self or cross. Moreover, by observing the segregation ratios among the progeny after appropriate crosses, we can deduce the genotypes of the parents.

In a recent analysis, in which we examined the behaviour of many of our stocks through selfs and intercrosses of type IIs and type Is and after crosses between type Ils and type Is, we found convincing evidence in support of the model and identified two type II and three type I genotypes (Tilney-Bassett et al., 1992). In this paper we describe an investigation in the classical Mendelian manner in which we follow a single cross between two different type I plants and score the parents, the $F_{1}$ hybrid progeny and the $F_{2}$ and backcross generations.

\section{Materials and methods}

One cultivar used as a parent in this investigation is believed to be 'Alde'. Its name was originally unknown to us and so we called it 'Darlington Orange Red' (DOR) after Professor C. D. Darlington from whom it was a gift (Almouslem, 1988); we have retained the original abbreviation. Two other parents, both white flowered, are 'W1' and 'W2'. The former was a seedling derived from selfing the green form of 'Mrs J. C. Mappin' and the latter a seedling derived from the cross between the same 'Mrs J. C. Mappin' and the green form of 'Flower of Spring'. The white-over-green chimera 'Flower of Spring' (FS) was used as a standard source of mutant plastids.

We have mentioned already the results of selfing and intercrossing the three parents 'DOR', 'W1' and 'W2', which showed that they were true-breeding (TilneyBassett et al., 1992). In the present paper we look at the $F_{2}$ progeny derived from selfing the $F_{1}$ hybrids between 'W1' or 'W2' and 'DOR' and at the backcrosses of the $F_{1}$ hybrids with their alternative parents.

Each green leaved parent, each individual $F_{1}$ hybrid and each individual member of the $F_{2}$ or backcross generation was classified as type I or type II by crossing it with the variegated form of 'Flower of Spring', as a source of mutant plastids, and then observing, under a 
Table 1 Matrix of crosses of type II and type I genotypes showing the expected phenotypic ratios after nine selfs and 36 crosses, based on the hypothesis of a two-gene complementary model of plastid inheritance

\begin{tabular}{|c|c|c|c|c|c|c|c|c|c|c|}
\hline Phenotypes & Genotypes & $\begin{array}{l}\text { II } \\
\text { PrIPrl } \\
\text { Pr2Pr2 }\end{array}$ & $\begin{array}{l}\text { II } \\
\text { Prlpr1 } \\
\text { Pr2Pr2 }\end{array}$ & $\begin{array}{l}\text { II } \\
\text { PrIPrI } \\
\text { Pr2pr2 }\end{array}$ & $\begin{array}{l}\text { II } \\
\text { PrlprI } \\
\text { Pr2pr2 }\end{array}$ & $\begin{array}{l}\text { I } \\
\text { prlprl } \\
\text { Pr2Pr2 }\end{array}$ & $\begin{array}{l}\text { I } \\
\text { PrlPrI } \\
\text { pr2pr2 }\end{array}$ & $\begin{array}{l}\text { I } \\
\text { prlprl } \\
\text { Pr2pr2 }\end{array}$ & $\begin{array}{l}\text { I } \\
\text { Prlprl } \\
\text { pr2pr2 }\end{array}$ & $\begin{array}{l}\text { I } \\
\text { prlprl } \\
\text { pr2pr2 }\end{array}$ \\
\hline II & $\begin{array}{l}\text { PrIPrI } \\
\text { Pr2Pr2 }\end{array}$ & II & II & II & II & II & II & II & II & II \\
\hline II & $\begin{array}{l}\text { Prlprl } \\
\text { Pr2Pr2 }\end{array}$ & & 3II:1I & II & 3II:1I & 1II:1I & II & 1II:1 I & 3II:1I & 1II:1I \\
\hline II & $\begin{array}{l}\text { PrIPrI } \\
\text { Pr2pr2 }\end{array}$ & & & 3II:1I & 3II:1I & II & 1II:1I & 3II:1I & 1II:1I & 1II:1I \\
\hline II & $\begin{array}{l}\text { Prlprl } \\
\text { Pr2pr2 }\end{array}$ & & & & 9II:7I & 1II:1I & 1II:1I & 3II:5I & $3 I I: 5 I$ & 1II:3I \\
\hline I & $\begin{array}{l}\text { prlprl } \\
\text { Pr2Pr2 }\end{array}$ & & & & & I & II & I & 1II:1 I & I \\
\hline I & $\begin{array}{l}\text { PrlPrl } \\
\text { pr2pr2 }\end{array}$ & & & & & & I & 1II:1I & 1 & I \\
\hline I & $\begin{array}{l}\text { prlprl } \\
\text { Pr2pr2 }\end{array}$ & & & & & & & I & 1II:3I & I \\
\hline I & $\begin{array}{l}\text { Prlprl } \\
\text { pr2pr2 }\end{array}$ & & & & & & & & 1 & I \\
\hline I & $\begin{array}{l}\text { prlprl } \\
\text { pr2pr2 }\end{array}$ & & & & & & & & & I \\
\hline
\end{tabular}

stereomicroscope at $\times 10$ magnification, the frequencies of green, variegated and white embryos. The mother plant was then classified according to the pattern of embryos: type I G $>V>W$, type II $G>V<W$ (see Introduction). In some type I families there were green and variegated but no white embryos and in others neither variegated nor white embryos. In type II families, green and white embryos were both more frequent than variegated embryos. For over 95 per cent of families the classification worked well but for the remainder additional ways of separating type I and type II plants were required. As a result of previous experience, we have slightly modified the criteria used in this investigation. Hence, when for a putative type II classification the frequency of green embryos was very high, we decided that at least 10 per cent of embryos should be variegated plus white (previously 6 per cent) and that there should be at least five (previously three) more white than variegated embryos; and that when variegated embryos were absent at least 10 per cent (previously 6 per cent) of embryos should be white. Also, when the frequency of variegated embryos was high, we decided that there should be at least five (previously three) more white than variegated embryos. At least 20 embryos were scored for each family (Tilney-Bassett \& Almouslem, 1989) and usually many more.

Determining whether all progeny were alike or whether true segregation occurred did not require large progeny sizes but distinguishing with confidence between one segregation ratio and another often did (Mather, 1951) and, regrettably, our progeny sizes were usually too small. To reduce this problem, we put more emphasis on the interpretation of the collective results from selfs, from $F_{1}$ crosses, from $F_{2}$ and from backcrosses. In this way we expected to obtain enough information to be able to recognize the genotypes involved by the patterns of segregation. According to the complementary gene model under test, the set of Mendelian ratios expected from selfing and by crossing within type I plants is not the same as from selfing and by crossing within type II plants and yet another set of ratios is found after crosses between the two types (see Introduction). The occurrence of some patterns is so unique that it immediately defines the parental genotypes; in other cases the possible genotypes are reduced to alternatives, which further crosses may readily separate. Hence, by using several tests we expected to define each genotype exactly and if this proved possible the model would be vindicated.

In making the chi-square tests of the goodness of fit between observed data and expected ratios, we have not tested progenies of less than ten individuals and we have not applied the Yates correction to allow for the small size of many segregating families. We do, however, make a correction to allow for a slight excess of type II plants, as inferred from data, which is explained in the results. 


\section{Results}

The results of selfing and intercrossing the three type I plants are shown in Table 2. Two of these, 'W1' and 'W2', both after selfing and after crossing between them, produced progeny all of which proved to be of the type I phenotype. Subsequent analysis suggests that they were of identical genotype with respect to genes controlling the pattern of plastid inheritance. We regard them as interchangeable in the crosses that follow. The third type I plant, 'DOR' was also truebreeding. When, however, either the true-breeding

Table 2 Segregation into type II and type I progeny after selfing or intercrossing type I parents. The results are classified in accordance with the interpretation that there are two genotypes: PrlPrl, pr2pr2 and prlprl, Pr2pr2

\begin{tabular}{|c|c|c|c|c|c|c|c|c|}
\hline \multirow[b]{3}{*}{ Parental lines } & \multicolumn{4}{|c|}{ Segregation pattern } & \multirow[b]{3}{*}{ Total } & \multirow[b]{3}{*}{$\chi^{2}$} & \multirow[b]{3}{*}{ d.f. } & \multirow[b]{3}{*}{$l$} \\
\hline & \multicolumn{2}{|c|}{ Expected } & \multicolumn{2}{|c|}{ Observed } & & & & \\
\hline & II & I & II & I & & & & \\
\hline \multicolumn{9}{|c|}{ PrIPrl, pr $2 p r 2 \times \operatorname{Pr} I P r 1, p r 2 p r 2$} \\
\hline W1 or W2:S1 & All & I & 0 & 52 & 52 & & & \\
\hline $\begin{array}{l}\mathrm{W} 1 \times \mathrm{W} 2: \mathrm{F}_{\mathrm{i}} \\
\text { prlprl } \operatorname{Pr} 2 p r 2 \times p r l p r\end{array}$ & All & $\mathrm{I}$ & 0 & 49 & 49 & & & \\
\hline $\begin{array}{l}\text { prlprl, Pr } 2 p r 2 \times p r l p r 1 \\
\text { DOR: S1 }\end{array}$ & $\begin{array}{l}\operatorname{Pr} 2 p \\
\text { All }\end{array}$ & $2^{2}$ & \multicolumn{3}{|c|}{ prlprl, Pr2pr $2 \times p r 1 p r 1, \operatorname{Pr} 2 p r 2$} & & & \\
\hline \multicolumn{9}{|c|}{ PrlPrl, pr $2 p r 2 \times p r 1 p r 1, \operatorname{Pr} 2 p r 2$} \\
\hline W1 or W2 $\times$ DOR: $F_{1}$ & 1 & 1 & 36 & 37 & 73 & 0.014 & 1 & $0.95-0.90$ \\
\hline
\end{tabular}

Table 3 Segregation into type II or type I progeny after $(a)$ selfing type I $F_{1}$ hybrids and $(b)$ selfing type II $F_{1}$ hybrids. The results are classified in accordance with the interpretation that the type I F, hybrids have the genotype PrIprl, pr2pr2 and the type II $F_{1}$ hybrids have the genotype Prlprl, Pr2pr2

\begin{tabular}{|c|c|c|c|c|c|}
\hline \multirow[b]{3}{*}{$F_{1}$ hybrids } & \multicolumn{2}{|c|}{ Segregation pattern } & & & \\
\hline & Expected & Observed & & & \\
\hline & II & II & Total & d.f. & $P$ \\
\hline
\end{tabular}

(a) Type I selfs: Prlprl, pr2pr2 2 Prlprl, pr2pr2

$\begin{array}{llllrr}\mathrm{DOR} \times \mathrm{W} 1 / 1 & \text { All } & \text { I } & 3 & 54 & 57 \\ \mathrm{~W} 1 \times \mathrm{DOR} / 3 & \text { All } & \text { I } & 1 & 72 & 73 \\ \mathrm{~W} 1 \times \mathrm{DOR} / 4 & \text { All } & \text { I } & 2 & 84 & 86 \\ \mathrm{DOR} \times \mathrm{W} 1 / 6 & \text { All } & \text { I } & 0 & 40 & 40 \\ \mathrm{DOR} \times \mathrm{W} 2 / 9 & \text { All } & \mathrm{I} & 0 & 7 & 7 \\ \mathrm{DOR} \times \mathrm{W} 2 / 13 & \text { All } & \mathrm{I} & 0 & 4 & 4 \\ \mathrm{DOR} \times \mathrm{W} 1 / 14 & \text { All } & \mathrm{I} & 0 & 57 & 57 \\ \mathrm{DOR} \times \mathrm{W} 2 / 20 & \text { All } & \mathrm{I} & 0 & 1 & 1 \\ \text { Total } & & & 6 & 319 & 325\end{array}$

(b) Type II selfs: Prlprl, Pr2pr $2 \times$ PrIprl, Pr2pr 2

\begin{tabular}{|c|c|c|c|c|c|c|c|c|}
\hline $\mathrm{DOR} \times \mathrm{W} 2 / 7$ & 9 & : & 32 & 15 & 47 & 2.675 & 1 & $0.20-0.10$ \\
\hline $\mathrm{W} 1 \times \mathrm{DOR} / 8$ & 9 & : & 22 & 34 & 56 & 6.549 & 1 & $0.05-0.01$ \\
\hline $\mathrm{DOR} \times \mathrm{W} 1 / 10$ & 9 & : & 21 & 24 & 45 & 1.679 & 1 & $0.70-0.50$ \\
\hline $\mathrm{W} 1 \times \mathrm{DOR} / 17$ & 9 & : & 27 & 23 & 50 & 0.103 & 1 & $0.90-0.70$ \\
\hline Total & & & & & & 11.006 & 4 & \\
\hline Pooled & 9 & 7 & 102 & 96 & 198 & 1.804 & 1 & $0.20-0.10$ \\
\hline Heterogeneity & & & & & & 9.202 & 3 & $0.05-0.01$ \\
\hline Adjusted pooled & & & 99 & 99 & 198 & 3.143 & 1 & $0.10-0.05$ \\
\hline
\end{tabular}


'W1' or 'W2' was crossed with the true-breeding 'DOR', the $F_{1}$ hybrid progeny proved to have either the type I or the type II genotype in equal frequency. The $1: 1$ ratio indicates that the parents are of different genotype and that the genes are able to complement each other in the making of type II plants. In fact it is the result expected from the cross on the assumption that 'W1' and 'W2' have the genotype Pr1Pr1,pr2pr2 and 'DOR' the genotype pr1pr1,Pr2pr2, as indicated (Table 1). The same result is also expected if the genotypes are reversed (i.e. for every dominant allele replace with a recessive and for every recessive replace with a dominant) but after having defined one genotype from the outset the other is fixed.

Thirteen of the $F_{1}$ hybrids, of which eight were type I and five type II, were tested further by selfing the majority of them and by backcrossing each to both parents. Although the data are somewhat deficient for some hybrids, selfing the type I $F_{1} s$ shows that these are largely true-breeding (Table $3 \mathrm{a}$ ), whereas after selfing the type II $F_{1} s$ their progeny clearly segregate into type IIs and type Is (Table 3b). The ratio of 9 type II: 7 type I fits our interpretation of the original cross in which these type IIs are presumed to be double heterozygotes (Table 1). Three out of four families give a good fit with the 9:7 ratio as does the pooled data, although this does not by itself exclude the $1: 1$ ratio with which the data also fit. The 1:1 ratio, however, is normally associated with the backcross between a heterozygote for a single gene and a homozygous recessive and is not normally expected after selfing, except through the modification of a monohybrid 3:1 ratio to $1: 1$ owing to the action of a gametophytic lethal.

When the type I $F_{1} s$ were backcrossed to 'W1' or 'W2', the progeny were again largely type I. As after selfing, there were again a few type IIs (Table 4a). In total (Tables 3 and 4 ) there were 29 type IIs among 866 type Is, i.e. 3.24 per cent type IIs. Although a few of these might have been rare contaminants, most are likely to be the result of misclassification; i.e. we do not think that they were genuine segregants. As they probably occurred in all our crosses, we must have underscored our type I class in segregating progeny by this percentage and so, to allow for this, we have pre-

Table 4 Segregation into type II or type I progeny after backcrossing (a) type I $F_{1}$ hybrids to $\mathrm{W} 1$ or $\mathrm{W} 2$ and (b) type II $\mathrm{F}_{1}$ hybrids to $\mathrm{W} 1$ or $\mathrm{W} 2$. The results are classified in accordance with the interpretation that the type $\mathrm{I}_{1}$ hybrids have the genotype Prlprl, pr2pr2 and the type II $\mathrm{F}_{1}$ hybrids have the genotype Prlprl, Pr2pr2

\begin{tabular}{|c|c|c|c|c|c|c|c|c|}
\hline \multirow[b]{3}{*}{$F_{l}$ hybrids } & \multicolumn{4}{|c|}{ Segregation pattern } & \multirow[b]{3}{*}{ Total } & \multirow[b]{3}{*}{$\chi^{2}$} & \multirow[b]{3}{*}{ d.f. } & \multirow[b]{3}{*}{$P$} \\
\hline & \multicolumn{2}{|c|}{ Expected } & \multicolumn{2}{|c|}{ Observed } & & & & \\
\hline & II & I & II & 1 & & & & \\
\hline \multicolumn{9}{|c|}{ (a) Type I $\times \mathrm{W} 1$ or $\mathrm{W} 2: \operatorname{Pr} 1 p r 1, p r 2 p r 2 \times \operatorname{Pr} 1 \operatorname{Pr} 1, p r 2 p r 2$} \\
\hline$(\mathrm{DOR} \times \mathrm{W} 1 / 1) \times \mathrm{W} 1$ & All & I & 10 & 85 & 95 & & & \\
\hline$(\mathrm{W} 1 \times \mathrm{DOR} / 3) \times \mathrm{W} 1$ & All & I & 0 & 70 & 70 & & & \\
\hline$(\mathrm{W} 1 \times \mathrm{DOR} / 4) \times \mathrm{W} 1$ & All & I & 0 & 45 & 45 & & & \\
\hline$(\mathrm{DOR} \times \mathrm{W} 1 / 6) \times \mathrm{W} 1$ & All & I & 0 & 77 & 77 & & & \\
\hline$(\mathrm{DOR} \times \mathrm{W} 2 / 9) \times \mathrm{W} 2$ & All & I & 3 & 82 & 85 & & & \\
\hline$(\mathrm{DOR} \times \mathrm{W} 2 / 13) \times \mathrm{W} 2$ & All & I & 0 & 62 & 62 & & & \\
\hline$(\mathrm{DOR} \times \mathrm{W} 1 / 14) \times \mathrm{W} 1$ & All & I & 3 & 68 & 71 & & & \\
\hline$(\mathrm{DOR} \times \mathrm{W} 2 / 20) \times \mathrm{W} 2$ & All & I & 7 & 58 & 65 & & & \\
\hline Total & & & 23 & 547 & 570 & & & \\
\hline \multicolumn{9}{|c|}{ (b) Type II $\times \mathrm{W} 1$ or W2: Pr1prl, Pr2pr2 $\times \operatorname{Pr} 1 P r 1, p r 2 p r 2$} \\
\hline$(\mathrm{DOR} \times \mathrm{W} 2 / 7) \times \mathrm{W} 2$ & 1 & 1 & 40 & 34 & 74 & 0.486 & 1 & $0.50-0.30$ \\
\hline$(\mathrm{W} 1 \times \mathrm{DOR} / 8) \times \mathrm{W} 1$ & 1 & 1 & 21 & 20 & 41 & 0.024 & 1 & $0.90-0.70$ \\
\hline$(\mathrm{DOR} \times \mathrm{W} 1 / 10) \times \mathrm{W} 1$ & 1 & 1 & 53 & 39 & 92 & 2.130 & 1 & $0.20-0.10$ \\
\hline$(\mathrm{DOR} \times \mathrm{W} 2 / 16) \times \mathrm{W} 2$ & 1 & 1 & 33 & 31 & 64 & 0.062 & 1 & $0.90-0.70$ \\
\hline$(\mathrm{W} 1 \times \mathrm{DOR} / 17) \times \mathrm{W} 1$ & 1 & $: 1$ & 55 & 31 & 86 & 6.698 & 1 & $0.01-0.001$ \\
\hline Total & & & & & & 9.400 & 5 & \\
\hline Pooled & & & 201 & 156 & 357 & 5.672 & 1 & $0.05-0.01$ \\
\hline Heterogeneity & & & & & & 3.728 & 4 & $0.50-0.30$ \\
\hline Adjusted pooled & & & 197 & 160 & 357 & 3.835 & 1 & $0.10-0.05$ \\
\hline
\end{tabular}


sented an adjusted pooled segregation. The adjusted segregation still fits with the assumed 9:7 ratio (Table $3 \mathrm{~b})$, although less well than the non-adjusted value.

When the type II $F_{1} s$ were backcrossed to 'W1' or 'W2', four out of five families segregated in a good agreement with the 1:1 ratio (Table 1) expected from this backcross (Table 4b). The shortage of type Is in several families was, however, particularly marked in one family and in the pooled result but the adjusted pooled data fitted the $1: 1$ ratio at the 5 per cent level of significance.

The set of backcrosses of the $F_{1}$ hybrids to the 'DOR' parent are displayed in Table 5. Six out of seven type I $F_{1} s$ have progeny which segregated in the expected ratio of 1 type II:3 type 1 (Table 1 ) with a reasonable fit, as did the overall pooled data (Table 5a). Several of the individual families showed a deficit of type I plants as did the pooled data and the fit with the adjusted pooled value was much improved. After the backcrosses to the type II $F_{1} s$, four out of five families had a good fit with the expected 3:5 ratio (Table 1) but one family with a poor fit was especially low on type I plants (Table $5 \mathrm{~b}$ ). Nevertheless, the overall fit was good and the adjusted fit still better.

In addition to scoring the frequencies of maternal, biparental and paternal zygotes (embryos), we estimated the proportion of maternal (green) plastids transmitted by 18 segregating families to their embryo progenies (Tilney-Bassett \& Birky, 1981) for each of the two types (Table 6). Altogether from the 18 families we scored 655 plants as type I and 492 plants as type II. For each group of plants from one family, classified as type I or type II, we tabulated the number of plants scored, the largest and smallest value, the mean and standard error (shown in Amoatey (1991) but not in Table 6), the variance and the 95 per cent confidence limits. We also determined whether any value was an outlier. The large variances within groups of type I and type II plants in each family were in agreement with earlier observations (Tilney-Bassett \& Almouslem, 1989). Invariably, type II families showed larger variances than type Is but these were reasonably homogeneous. The type Is were highly skewed having many plants exhibiting a pure maternal transmission of plas-

Table 5 Segregation into type II or type I progeny after backcrossing (a) type I $F_{1}$ hybrids to DOR and (b) type II $F_{1}$ hybrids to DOR. The results are classified in accordance with the interpretation that the type I F, hybrids have the genotype Prlprl, pr2pr2 and the type II $\mathrm{F}_{1}$ hybrids have the genotype $\operatorname{Pr} 1$ prl, Pr2pr2

\begin{tabular}{|c|c|c|c|c|c|c|c|c|c|}
\hline \multirow[b]{3}{*}{$F_{1}$ hybrids } & \multicolumn{5}{|c|}{ Segregation pattern } & \multirow[b]{3}{*}{ Total } & \multirow[b]{3}{*}{$\chi^{2}$} & \multirow[b]{3}{*}{ d.f. } & \multirow[b]{3}{*}{$P$} \\
\hline & \multicolumn{3}{|c|}{ Expected } & \multicolumn{2}{|c|}{ Observed } & & & & \\
\hline & II & & I & II & I & & & & \\
\hline \multicolumn{10}{|c|}{ (a) Type I× DOR: Prlpr1, pr $2 p r 2 \times p r 1 p r 1$, Pr $2 p r 2$} \\
\hline$(\mathrm{DOR} \times \mathrm{W} 1 / 1) \times \mathrm{DOR}$ & 1 & $:$ & 3 & 30 & 57 & 87 & 4.172 & 1 & $0.05-0.01$ \\
\hline$(\mathrm{W} 1 \times \mathrm{DOR} / 3) \times \mathrm{DOR}$ & 1 & : & 3 & 20 & 66 & 86 & 0.139 & 1 & $0.90-0.70$ \\
\hline$(\mathrm{W} 1 \times \mathrm{DOR} / 4) \times \mathrm{DOR}$ & 1 & : & 3 & 27 & 74 & 101 & 0.162 & 1 & $0.70-0.50$ \\
\hline$(\mathrm{DOR} \times \mathrm{W} 1 / 6) \times \mathrm{DOR}$ & 1 & : & 3 & 14 & 44 & 58 & 0.023 & 1 & $0.90-0.70$ \\
\hline$(\mathrm{DOR} \times \mathrm{W} 2 / 9) \times \mathrm{DOR}$ & 1 & : & 3 & 21 & 58 & 79 & 0.106 & 1 & $0.90-0.70$ \\
\hline$(\mathrm{DOR} \times \mathrm{W} 2 / 13) \times \mathrm{DOR}$ & 1 & : & 3 & 4 & 9 & 13 & 0.231 & 1 & $0.70-0.50$ \\
\hline$(\mathrm{DOR} \times \mathrm{W} 1 / 14) \times \mathrm{DOR}$ & 1 & : & 3 & 26 & 50 & 76 & 3.439 & 1 & $0.10-0.05$ \\
\hline Total & & & & & & & 8.272 & 7 & \\
\hline Pooled & & & & 142 & 358 & 500 & 3.083 & 1 & $0.10-0.05$ \\
\hline Heterogeneity & & & & & & & 5.189 & 6 & $0.90-0.70$ \\
\hline Adjusted pooled & & & & 130 & 370 & 500 & 0.267 & 1 & $0.70-0.50$ \\
\hline \multicolumn{10}{|c|}{ (b) Type II $\times$ DOR: Prlprl, Pr2pr2 2 pr1pr1, Pr $2 p r 2$} \\
\hline $\mathrm{DOR} \times(\mathrm{DOR} \times \mathrm{W} 2 / 7)$ & 3 & : & 5 & 9 & 30 & 39 & 2.340 & 1 & $0.20-0.10$ \\
\hline$(\mathrm{W} 1 \times \mathrm{DOR} / 8) \times \mathrm{DOR}$ & 3 & : & 5 & 7 & 10 & 17 & 0.098 & 1 & $0.90-0.70$ \\
\hline$(\mathrm{DOR} \times \mathrm{W} 1 / 10) \times \mathrm{DOR}$ & 3 & $:$ & 5 & 6 & 18 & 24 & 1.600 & 1 & $0.70-0.50$ \\
\hline$(\mathrm{DOR} \times \mathrm{W} 2 / 16) \times \mathrm{DOR}$ & 3 & : & 5 & 23 & 40 & 63 & 0.026 & 1 & $0.90-0.70$ \\
\hline$(\mathrm{W} 1 \times \mathrm{DOR} / 17) \times \mathrm{DOR}$ & 3 & : & 5 & 46 & 44 & 90 & 7.114 & 1 & $0.01-0.001$ \\
\hline Total & & & & & & & 11.178 & 5 & \\
\hline Pooled & & & & 91 & 142 & 233 & 0.241 & 1 & $0.70-0.50$ \\
\hline Heterogeneity & & & & & & & 10.937 & 4 & $0.20-0.10$ \\
\hline Adjusted pooled & & & & 86 & 147 & 233 & 0.035 & 1 & $0.90-0.70$ \\
\hline
\end{tabular}


Table 6 Percentage estimates of maternal (green) plastid transmission within groups of type I and type II plants in 18 segregating families. The data show the number of plants scored within each type from each family, the highest and lowest value plant, the variance among the plants and their 95 per cent confidence intervals. The first outlier, if present, is marked *

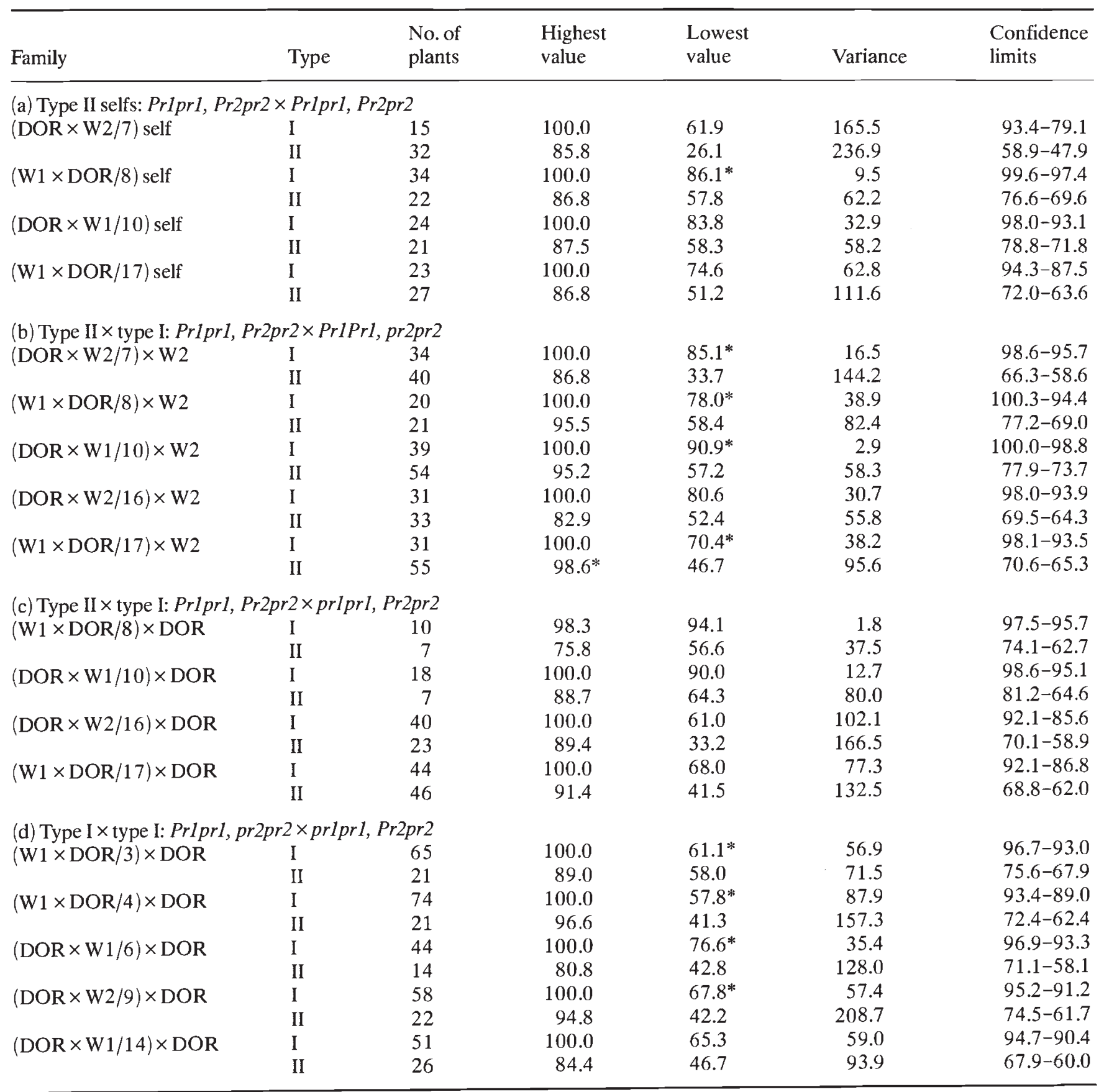

tids. The 95 per cent confidence limits clearly separated type I and type II individuals as distinct groups. Within families, there was no overlap of confidence limits, although with respect to actual values the lowest type I and highest type II overlapped in 16 of the 18 families. These extreme values fell outside the confidence limits and sometimes proved to be significant outliers, which suggests that they may have been classified in the wrong group but as there were more outliers among type I families (9) than among type II families (1) this would tend to increase the number of type IIs. Taking together 18 segregating families, the confidence interval for maternal plastid transmission within type I plants was in the limits of 100 to 79.1 whereas for type II plants it fell within the limits of 81.2 to 47.9 , showing just a slight overlap between the two. 
If, as suggested above, misclassification accounts for an excess of type IIs, these are probably to be found among the many plants with maternal plastid estimates outside the confidence limits, although not so far out as to be recognized as outliers.

\section{Discussion}

The precise scoring of these plants was difficult to achieve because there was always a small group of plants that gave frequencies of green, variegated and white embryos that placed them on the overlapping edge of the type II and type I ranges. Although through past experience we have set out guidelines for distinguishing between type IIs and type Is by the pattern in the frequency of green, variegated and white embryos after crossing with variegated 'Flower of Spring' as a constant source of mutant plastids, the ultimate test is how they subsequently behave genetically. Based on the trueness of true-breeding type I families, we appear to have achieved a classification almost 97 per cent reliable, which is probably as close as we can reasonably expect. By making an adjustment for the 3 per cent error, we have obtained Mendelian segregation ratios in good overall agreement with the expected ratios with which we can feel confident. Even more important than the separate agreement with the expectation of a self or both backcrosses, is the joint agreement with all three. The two-gene complementary model indicates that there is only one type $I F_{1}$ hybrid genotype that produces type I plants on selfing, type I plants on backcrossing to the 'W1' or 'W2' parent and plants segregating in a ratio of 1 type II:3 type I after backcrossing to the 'DOR' parent (Table 1). Similarly, there is only one type II $\mathrm{F}_{1}$ hybrid genotype that produces plants segregating in a 9:7 ratio on selfing, a 1:1 ratio on backcrossing to ' $\mathrm{W} 1$ ' or ' $\mathrm{W} 2$ ' and a 3:5 ratio on backcrossing to 'DOR' (Table 1). All these ratios fit with the genotypes indicated in the tables and jointly they exclude all other genotypes. Hence, we feel convinced that our interpretation of the segregation data is correct. Thus, in summary, the type I parents 'W1' and 'W2' have the genotype $P r 1 P r 1, p r 2 p r 2$, the type I parent 'DOR' has the genotype prlprl,Pr2pr2, the eight type I hybrids have the genotype Prlprl,pr2pr2 and the five type II hybrids have the genotype Prlprl,Pr2pr2. We do not, however, exclude the likelihood that other genes are also involved. For instance, modification of the type II and type I patterns through polygenic effects has already been demonstrated (Tilney-Bassett \& Almouslem, 1989) and it seems likely that differences between families in the frequency of variegated progeny is also under polygenic control.
As the difference between type I and type II plants is dependent upon the female genotypes, it is within the female reproductive tract that we should expect to find the two $\operatorname{Pr}$ genes operating. This might prove to be an effect on the morphology of the female, for example, differences in style length, which affect the behaviour of the male pollen growing down the style. Or, perhaps the effect operates on the plastids directly after fertilization has taken place. There are many hypotheses that might be suggested and these now require examining. The knowledge of the precise genotypes of the females examined may prove to be highly relevant.

\section{Acknowledgements}

H. M. Amoatey is grateful to the Commission of The Association of Commonwealth Universities for the award of a Commonwealth Scholarship during the academic years 1987-1990 and also to the Atomic Energy Commission in Ghana for granting him leave of absence.

\section{References}

AMOATEY, H. M. 1991. Genetic studies in zonal pelargoniums. Ph.D Thesis, University of Wales, Swansea, UK.

ALmouslem, A. B. 1988. Qualitative and quantitative genetical studies in Pelargonium $\times$ Hortorum Bailey. Ph.D. Thesis, University of Wales, Swansea, UK.

CHIU, w. L., STUBBE, w. AND SEARS, B. B. 1988. Plastid inheritance in Oenothera: organelle genome modifies the extent of biparental plastid transmission. Current Genetics, 13, 181-189.

CORNU, A. AND DULIEU, H. 1988. Pollen transmission of plastidDNA under genotypic control in Petunia hybrida Hort. $J$. Hered., 79, 40-44.

DEREPAS, A. 1991. Contrôle génétique de la transmission des plastes d'origine paternelle chez Petunia hybrida Hort. Ph.D. Thesis, University of Bourgogne, France.

DEREPAS, A. AND DULIEU, H. 1992. Inheritance of the capacity to transfer plastids by the pollen parent in Petunia hybrida Hort. J. Hered., 83, 6-10.

DULIEU, H., DEREPAS, A. AND CORNU, A. 1990. Le role du pollen dans la transmission des chloroplastes et des mitochondries. Etude d'un cas particulier chez Petunia. Bull. Soc. bot. Fr., 137, 49-56.

KIRK, J. T. O. AND TILNEY-BASSETT, R. A. E. 1978. The Plastids: Their Chemistry, Structure, Growth and Inheritance, 2nd edn, Elsevier/North-Holland Biomedical Press, Amsterdam.

MATHER, K. 1951. The Measurement of Linkage in Heredity. Methuen and Co., London.

SHI, L., ZHU, T., MOGENSEN, H. L. AND SMITH, S. E. 1991. Paternal plastid inheritance in alfalfa: plastid nucleoid number within generative cells correlates poorly with plastid number and male plastid transmission strength. Current Genetics, 19, 399-401. 
TILNEY-BASSETT, R. A. E. 1973. The control of plastid inheritance in Pelargonium II. Heredity, 30, 1-13.

TILNEY-BASSETT, R. A. E. 1974. The control of plastid inheritance in Pelargonium III. Heredity, 33, 353-360.

TILNEY-BASSETT, R. A. E. 1975. Genetics of variegated plants. In: Birky, C. W. Jr, Perlman, P. S. and Byers, T. J. (eds), Genetics and Biogenesis of Mitochondria and Chloroplasts, Ohio State University Press, Columbus, pp. 268-308.

TILNEY-BASSETT, R. A. E. 1976. The control of plastid inheritance in Pelargonium IV. Heredity, 37, 95-107.

TILNEY-BASSETT, R. A. E. AND ABDEL-WAHAB, O. A. L. 1982. Irregular segregation at the $\operatorname{Pr}$ locus controlling plastid inheritance in Pelargonium: gametophytic lethal or incompatibility system? Theor. Appl. Genet., 62, 185-191.

TILNEY-BASSETT, R. A. E. AND ALMOUSLEM, A. B. 1989. Variation in plastid inheritance between pelargonium cultivars and their hybrids. Heredity, 63, 145-153.

TILNEY-BASSETT, R. A. E., ALMOUSLEM, A. B. AND AMOATEY, H. M. 1989. The complementary gene model for biparental plastid inheritance. In: Boyer, C. D., Shannon, J. C. and Hardison, R. C. (eds), Physiology, Biochemistry and Genetics of Nongreen Plastids, The American Society of Plant Physiologists, Rockville, Maryland, pp. 265-266.

TILNEY-BASSETT, R. A. E., ALMOUSLEM, A. B. AND AMOATEY, H. M. 1992. Complementary genes control biparental plastid inheritance in Pelargonium. Theor. Appl. Genet., 85, 317-324.

TILNEY-BASSETT, R. A. E. AND BIRKY, C. W. JR. 1981. The mechanism of the mixed inheritance of chloroplast genes in Pelargonium: evidence from gene frequency distributions among the progeny of crosses. Theor. Appl. Genet., 60, 43-53.

ZHU, T., MOGENSEN, H. L. AND SMITH, S. E. 1990. Generative cell composition and its relation to male plastid inheritance in Medicago sativa. Protoplasma, 158, 66-72.

ZHU, T., MOGENSEN, H. L. AND SMITH, S. E. 1991. Quantitative cytology of the alfalfa generative cell and its relation to male plastid inheritance patterns in three genotypes. Theor. Appl. Genet., 81, 21-26. 